tage of leaving the Minnesota Railroad and Warehouse Commission free to choose between methods of rate making in specific instances.

It is suggested that in those states where any doubt may exist as to the power of the regulatory body to choose between methods of rate making, the Wisconsin statute can be copied with good effect. Administrative discretion should be left free to apply any method which best suits the convenience of the particular case and promises substantial justice to the parties concerned. Freedom of choice under precautionary provisions for appellate review, may permit continued progress in the development of rate making methods, and be perhaps the best public policy in the long run.

\title{
SOME DISTINCTIVE FEATURES OF A LEGAL AID CLINIC COURSE
}

\author{
JoHN S. BradwaY*
}

$\mathbf{I}^{\mathrm{N}}$ NSTRUCTING students by means of a legal clinic is a comparatively new departure. This educational device, which has already found favor in other fields of training-for the physical sciences through laboratory work; for the social sciences through field work; for the medical field through highly organized hospital clinics, and for religious education through special assignments - is making its way slowly into the domain of law. It contrasts with earlier approaches to the task-the apprenticeship system, instruction by lecture and textbook and the case method. The clinical approach differs from each of these in objectives, in method of instruction, and in material or content. It deals with a mental process as common to the lawyer as the judicial process is common to the judge. It throws into relief a new responsibility of the law school toward the community. These three phases of the problem-the differences from other methods of education, the nature of the process of thinking common to all lawyers and the added responsibility of law schools to the community - are the subjects of this paper.

THE CLINIC METHOD OF INSTRUCTION AND THE OTHER MIETHODS

A. The Objectives of the Clinic Course.-The clinical method of instruction in law is designed to accomplish five primary objectives. First, like the apprenticeship system, it gives the student a practical course in

* Director, Legal Aid Clinic, Duke University.

I A fairly complete bibliography of the material on the subject of legal aid clinics will be found in 30 Mich. L. Rev. go5 (1932). 
practice as contrasted with a theoretical course. It adds experience with "law in action" to that already gained from "law in books." It bridges the gap between the theory of law school and the practice of the profession. ${ }^{2}$ But from this point on, modern clinical instruction in law schools has novel features.

Second, it acts somewhat as a forum where the student may synthesize his theoretical experience gained in the different courses, substantive as well as procedural, that he has taken. In them, the tools are forged; in it, one finds out how to apply one or more tools in the solution of actual unsolved human problems. Misuse or lack of control will result inevitably in serious detriment to the client and a consequent economic loss or lowering of the lawyer's prestige, so the element of public responsibility is present. The average law school curriculum cuts the seamless web of the law arbitrarily into segments, such as Contracts, Torts, Future Interests. A single clinic case may have ramifications in many fields of substantive law, as well as in the domain of practice. ${ }^{3}$ The rules of law must be blended, harmonized, and evaluated with respect to the living case. Consequently, the work is in no sense a review of other courses. Rather, it is a voyage of discovery. Sometimes materials in other courses are used. Often the student must deal with a field in which he has had no previous classroom instruction. In such work the seamless web quality of the law is brought forcibly to mind. Resourcefulness is at a premium. The benefits of study in the other courses are seen to be in the development of analytical powers, not merely in learning specific rules. The legal aid clinic student of necessity explores all legal avenues which promise even remotely a means of reaching the desired goal. He dare not risk his client's rights on any narrower survey. Hence, he comes in time to feel at home in the general field of law as he previously did in the more restricted limits of each one of the courses he had taken.

Third, viewing the law as one of the social sciences, the clinic student has the opportunity to study the client as a whole in relation to the community as a whole. This introduces a distinctly new element-the human equation. Not only the legal problems of the client but all his problemssocial, economic and otherwise - should pass in review. Before advising

2 There is a substantial amount of literature attacking legal education for failure to bridge adequately this gap. For example, Alfred Z. Reed, The Missing Element in Legal Education (x929); Jerome Frank, What Constitutes a Good Legal Education? xg A.B.A. Jour. 723 (1933).

3 The variety of problems arising in legal aid clinic from the case of a single individual is a most interesting field for study. As examples, see the following cases in the Duke Legal Aid Clinic: Nos. 69, 54r, 5or. 
or acting, the student must have as complete a picture as possible of the human being with whom he is dealing. Only with this is he prepared to decide what he is to do with the case. The ultimate goal, and the means of reaching it, may be achieved by the use of resources in the field of law or in the field of some other professional activity, such as medicine, social work, or religion, or by a combination of several of the social or physical sciences. Hence, the approach to the material is unlike that in other law school courses. The client is not always to be satisfied by the statement, however accurate, that such and such is the law. Often that is merely the point of departure. He insists on being told what to do. Hence clinical training takes AB, XY, Greenacre, My Old Horse Susan and other symbols which have done yeoman service in hypothetical cases and clothes them with fiesh and blood and other objective reality. The dissatisfied client who pays for "A" grade work and receives legal services valued at "C -" may report the situation to a grievance committee or broadcast his lawyer's inefficiency to the four winds. ${ }^{4}$ Preparedness to meet such situations comes from grim experience with actual clients.

Fourth, the clinic student faces the problems of legal etiquette as contrasted with legal ethics. He learns to distinguish those swift unwritten techniques which are characteristic of the best practitioners and are not found in the armory of the less effective members of the bar.

Finally, the clinic course introduces the student to the case at the beginning rather than at the end. It forces him to think constructively and to plan a campaign..$^{5}$ The process is quite different from asking him to analyze a completed case embalmed on a printed page. By analogy, a medical school would hardly allow one of its students to treat a living patient unless the embryo physician had advanced further in his studies than the dissection of a cadaver. This is no reflection on the importance of such dissection. It is apparent rather that the clinical objectives bring

4 As examples of dissatisfied clients, note the following cases in the Duke Legal Aid Clinic involving complaints against members of the bar: Nos. $1,32,45,75,512,585,592$. The procedure for handling these cases sometimes involves a courtesy letter to the attorney in question. At other times the case is taken up directly with the grievance committee. During the last few years legal aid societies have collected statistics of complaints against lawyers. In r924, fifteen societies reported 976 such cases. In r930, seventeen sacieties reported 1628 . For the procedure employed by legal aid societies generally in handling such claims see, Reports of Committees for $1932-1933$, p. 59, discussed at Convention of National Association of Legal Aid Organizations held in Chicago, Ill., October 5 and 6, 1933 .

${ }^{5}$ For material indicating tentatively the nature and extent of this process see, Bradway, Supplement No. 2 of the Handbook of the Legal Aid Clinic (1933), c. I "Suggestions for Recording the Plan of Campaign."

Definite instruction in this work is given in the clinic course at Duke University. 
within our mental horizon a series of factors which are of significance in the educational field. We compare them with the elements in the other systems by which students have been transformed into lawyers.

B. The Unique Elements in the Clinical Approach.-The clinic course differs from other methods of instruction in approach, in method, and in material or content. It is because of the last four objectives mentioned in the foregoing section that the clinic instruction differs from the apprenticeship of an earlier era of legal education. That period may not now be recaptured, but that is no reason for keeping certain of its benefits beyond the reach of present day law students. Our problem is how to fit a new piece of improved machinery into an existing system which has outgrown apprenticeships.

Comparing the clinical method with instruction by lectures and textbooks, we find a wide divergence. The approach of the textbook method seems to be to place in the mind of the student a body of rules of law, concisely stated. In the clinic course knowledge of the rules of law is only one factor in a great multitude of elements which go to make up a lawyer's mental fibre. Flexibility of mind, resourcefulness, initiative, imagination, discretion and judgment in the use of the power of legal sanctions rather than a knowledge of a set of rules are the characteristics by which we judge students. The methods of instruction differ because in a clinic the student is brought in contact with flesh-and-blood clients, clerks of court, opposing counsel, witnesses and other people-rather than with books or a lecturer. The training results in personality development. Experience in dealing with unexpected situations is emphasized rather than the ability to reach into the musty closets of one's memory and drag out a rule of law. Finally, the materials differ. Again, in one case it is law in books; in the other, law in action.

The distinctions between the clinical method and the case method of instruction are equally important. The approach of the case method includes an effort to develop in the student the power of thinking analytically and to familiarize him with the original material of court decisions rather than the previously digested information in textbooks. ${ }^{6}$ The clinic is designed to teach the student to think constructively as well as analytically - to act creatively as a lawyer in addition to thinking like a judge or legal scholar. The case method is conducted by supervised class discussion under laboratory conditions. In the clinic office the client is a third party, present in person or by proxy. This makes a great difference. As

${ }^{6}$ Among the material on this subject perhaps as objective a study as any is contained in Redlich, The Common Law and the Case Method (I9I4). 
there are no limitations on the situation presented one cannot prepare for it as by reading assignments but must face the door that opens to let in a novel situation. Neither student or instructor can anticipate the details of the initial contact. This presents a new kind of challenge. If the student possesses qualities such as dependability, leadership, calmness under fire, the clinical experience brings them out.

The case method, for its raw material, takes usually a completed decision of the court or a hypothetical set of facts. The clinic starts with a raw human problem, often untouched by the legal mind and one that may never become the subject of court decision. The clinic course is not just another course. It is a new approach.

All this is just another way of saying that the main distinction between the two is that they deal with different aspects of a series of mental processes found in the activities of the legal profession. It is important for us to consider just what mental processes are required in the handling of a case. Otherwise we cannot intelligently provide a student with opportunities to prepare himself for the tests he will be forced to undergo at the hands of the public.

THE MENTAL PROCESS OF THE PRACTICING LAWYER

Justice Cardozo has made familiar the Judicial Process. ${ }^{7}$ This is a mental exercise by which the legally relevant factors in a case are evaluated and a decision reached as to what is, or what should be, the law. The material necessary for its functioning is found to a large extent in the records of cases coming for decision in an appellate court. It is, however, only one part of that more extensive procedure. One asks-where do the records in appellate cases come from, and what sort of mental process is required to produce a condition of orderliness sufficient to warrant a lawyer in submitting a question to judicial determination.

The whole process, extended to the full, contemplates the initial taking up of a human difficulty and its ultimate solution by the resources of the law. The first stage consists in gathering from lay minds, public records, and elsewhere, miscellaneous materials-some legal, some extra-legal. These must be tested for their relative usefulness to the client, translated into the field of legal thought and organized, reduced to form on paper. The lawyer must make a series of decisions regarding them. Does the best solution lie by way of legal resources or should the client go to some other professional group to receive adequate treatment? Is the case capable of solution by conciliation, legislation, education procedures, or only by

7 Cardozo, The Nature of the Judicial Process (r928). 
litigation? Only a small proportion of the matters arising in a law office ever get into court. So the lawyer who knows only the technicalities of pleading is at a disadvantage. Even the ability to draw a complaint, draft a brief or argue a point of law is not enough. The practicing lawyer must be the master of many techniques.

The second stage in the disposition of a human problem involves the judicial process of taking these partially organized materials and refining them still further by a decision. The third stage is that allocated to the legal scholars, who inter alia, by comment and criticism, take the completed results of the lawyers and judicial processes and relate them to a scholarly and scientific system of law or discuss the lack of conformity.

If the foregoing is admitted to be a fair statement of the general legal process, then we see even more clearly the need for a difference in emphasis in training men to be lawyers as contrasted with the needs of those planning to be legal scholars. The practicing lawyer is engaged in the building process. He looks forward from the most scattered, uncoordinated materials. Starting at the beginning of a problem, he faces the kaleidoscopic life about him and must select from it bricks with which to build his case. $\mathrm{He}$ is the prospector digging for precious metals in the desert or lonely mountains. By the time the case gets to the legal scholar by way of the advance sheets, it has passed through two series of legal minds. Disorder, extraneous circumstances, among other factors, have been eliminated, until only the purely legal aspects of the controversy appear on paper. Here the scholar critic may take the refined metal and mould it into a thing of beauty. The artist sits down before a blank canvas or block of marble and creates. The critic evaluates the completed task according to recognized standards. While the same standards may be common to both, the approach is different. Hence training of the law student that does not visualize the creative approach ignores much that he will need most in his daily life. The tendency to regard such training as nothing more than a learning of certain trade routines may have had something to do with the disinclination of some lawyers to raise the level of their work to the field of art. ${ }^{8}$ Certainly in current legal education there is a place for emphasis on the training of the lawyer as such, so that when practicing law in the grand manner he may not in any case fail the court, the client, his profession or the community. If lawyers generally were taught to adhere to increasingly high standards of practice in all its

${ }^{8}$ In case No. 289 the Duke Legal Aid Clinic was called upon to help a mature lawyer untangle a snarl into which he had dragged himself by failure to read the rules relating to the taking of an appeal. The clinic staff, of course, could only surmise what the client thought of the way the case had been handled. 
phases, the materials out of which scholars build a legal system would become better in quality.

But the technical ability and a sense of ethical propriety, however highly developed, do not round out the stereotype lawyer who is the ideal leader. Of the other factors one of the most important is social vision. One need hardly repeat that lawyers are essential in building social programs of the future. To be able to make their contributions it is necessary that they be given a viewpoint which senses responsibility to the community.

Some men are moved by the printed word; others by personal contact with their fellows. It would be unfortunate for the leadership of the Bar and its public prestige if a wide range of opportunities were not afforded men to kindle their interest. Certainly there are law students to whom the plight of an individual client is a greater incentive to activity than any book, lecture, or classroom discussion. ${ }^{9}$ For these men an interpretation of the part which a lawyer may play in the broad field of public welfare, by the example of a carefully handled interview, a well tried case, a conciliation procedure, a bit of legislation, may be inspirational.

Human problems are innumerable. Of them, great quantities are solved in the fields of medicine or the social sciences and elsewhere. The outlook on life available to the legal profession is, at best, but a segment of the whole. But there is reason to urge the broadest possible understanding of community problems and a cooperative endeavor with the other professions in meeting them. The public is coming more and more to require it.

The law student who plans to practice law needs for his own sake to be aided in securing this broad viewpoint. The collective value to the profession and the public of a constantly increasing group of men with a desire toward this sort of intellectual leadership would be very great. We come to consider then the obligation of the law school to provide such educational opportunities.

\section{RESPONSIBILITY OF THE LAW SCHOOL TOWARD COMMUNITY AND INDIVIDUAL CLIENT}

The legal aid clinic augments and extends the educational opportunities offered by the other courses. It directs the attention of the student to

\footnotetext{
9 In case No. 6ri of the Duke Legal Aid Clinic the student awoke to the plight of a man charged with forgery. After securing his acquittal in a hotly contested case, the student brought to bear upon the client the resources of the School of Religion and the School of Medicine providing an excellent example of inter-professional cooperation in the solution of a specific human being's problems. See also, A Problem for Coordinated Medical and Legal Talent, Wiley D. Forbus and John S. Bradway, 26 Southern Medical Jour., No. 9 (I933).
} 
the first part of the "legal process," just as the case method emphasizes the second, the law review work the third. It develops a viewpoint. Recognizing that law students who have this training are better prepared for certain tasks, we may inquire whether there is any obligation on the law school to train them. One may say that it is the duty of a law school to teach only law. Another may contend in favor of the exclusive importance of the analytical approach. Still another stresses the functional approach. Is there room for or value in a new technique based on factors which the clinic class may regard as important? The answer may be approàched from various angles. For our purposes the student himself is the main consideration. What does law school do for him as an individual? How does it prepare him to meet his future employers and clients on their own ground? As to that we may not generalize.

The practical problem faced by the student is one of adjustment to a new environment. While the situations may vary infinitely with the individual, it is possible to make certain specific classifications. One group of law graduates is headed for a business career, with legal training as a background. With them we have no particular concern because they pass out of the legal field. Of those who remain, by far the largest portion become practicing lawyers. After some years, a few of them may become judges. Only a handful go into the field of law teaching.

The faculty and the student both have some concern as to his fitness for his chosen work. While we have devices to check a man's analytical ability, his other characteristics have not as yet been brought within the province of orderly testing. Hence the existing process of legal education, unlike medicine, turns its men out without a guide in certain vital directions. A sense of devotion to the ideals of scholarship in a law student is an inadequate point of view with which to face situations with which legal scholarship has no concern. The consequences to the community and the individual of such oversight may be very grave.

The situation is comparable in some respects to the operation of a factory which, concentrating on the production of some particular article, allows valuable by-products to go to waste. Somewhere along the line the law student will face a client who is dissatisfied with the work done. When it comes to fixing responsibility for the mistake, there are three possible culprits - the student, the law school, the bar. The student frequently is the innocent victim of a system of education which prepares him for only one part of his task. The modern bar is not equipped, nor has it the time, to do thorough educational work supplementing the law school's task. In the last analysis the primary obligation to provide a well rounded program-no matter how much it costs or how difficult of ad- 
ministration-rests on the law school. The public, which is the final judge of values over a period of time, will be satisfied with nothing but the best product. In facing its share of this obligation to the public, the law school may take various extreme positions. It may insist that it has nothing but a limited responsibility or that from practical considerations it is doing the best it can. On the other hand, it may make reasonable efforts to explore these broader fields for the purpose of determining how effectively such training can be given.

Those law schools which have experimented with the clinic system even in small degree seem to be adopting the following attitude. For them a well rounded student as a prospective leader is to be preferred to the specialist. In spite of the fact that members of their faculties are admittedly specializing, they appreciate that a broad basis of preparation is likely to produce a more effective lawyer. Specialization may begin so early in a man's work as to dwarf his outlook. The student who has been introduced to a number of the situations with which he will have to deal, and who has received some instruction as to recognized ways and means of handling himself, seems more likely to turn out a leader whether or not he subsequently specializes.

In a situation where each critic measures the value of law school training from the background of his own experience, one can hardly outline dogmatically a perfect system. But one may study the failures which result from neglect of certain factors in legal education. The student suffers if he does not have clinical training. It is customary to judge the success of the educational process by its outstanding leaders. May it not be equally sound to base our study on the failures. The blame should be laid where it belongs.

Many men will never make well rounded lawyers. ${ }^{\mathrm{To}}$ As a result of train-

${ }^{x}$ The Iegal Aid Clinic student is more than a name or a location in the classroom. An adequate study of the man and his abilities would include a social case history and a complete psychiatric examination. In a sense the clinic experience is a very broad scale aptitude test. But it is aptitude for general practice rather than as a law student. Perhaps this study should parallel the student's work for three years instead of being limited to third year men. The work coming to a clinic organization is classifiable into the simplest sorts of work-studying the geography of the courthouse, securing information from public records, serving papers, which might be done profitably by first year men. In the second year certain briefing problems might be assigned. The interviewing of clients, preparation of plans of campaign and preparation for trial of cases would be reserved for the final year. Such a process would disclose strengths and weaknesses in time for both student and instructor to handle them.

In a sense the clinic work is a study of individual mistakes. They cover a wide range. Eventually they may be tabulated, studied, and preventive measures devised to anticipate them. Among the simpler errors are the following:

In case No. 6ro of the Duke Legal Aid Clinic the student was requested by counsel for the defendant to brief a point of law and assist at the trial. The student knew he should phone 
ing in the clinic work, students seem to fall into four distinct groups. There are a few at the top of the clinic class who give promise of being able to take care of themselves anywhere, and dispose satisfactorily of any law business that comes to them. These are by no means necessarily the ones who win the highest grades in other courses. A second group includes men who are highly effective in some limited respect-such as briefing-but are not well rounded. They may be lamentably ineffective in meeting the public. They may have no ability to attract business because they do not know how to inspire confidence. Yet in their own field they may be very able. Following these come a group of more or less mediocre men who are able to pass examinations and can practice law but who do not show any particular aptitude and are not likely to bring any particular glory to the law school from which they graduate. At the tail end are those who, for one reason or other, are so obviously unprepared for practice that the seasoning process ought to be continued with respect to them for some time.

If a law school, by the clinic device, were to coordinate more successfully its functions of keeping men out of the profession and acting as a stepping stone for admission to it, two important results would follow: First, it would be possible, after exposing the class to conditions closely approximating general practice, to separate from the student group all the men below a certain standard and to delay their entrance until they demonstrated satisfactory proficiency, dependability, social viewpoint,

counsel for the defense and have a conference. Catching sight of the name of an attorney in his notes and not stopping to think who the attorney was, he phoned. After the conversation had proceeded for a space, the student suddenly realized that he was talking to opposing counsel. He had the good judgment to reveal nothing further. Opposing counsel realizing the mistake courteously referred the student to defense counsel.

In case No. 555 of the Duke Legal Aid Clinic the student in preparing an advisory brief for a public official forgot that the legislature had met in 1933 . So his brief failed to include any consideration of the most recent statute on the subject.

In case No. 599 of the Duke Legal Aid Clinic the student had been assigned the task of drawing a document. It should have been ready by a certain day. On the preceding day the student deposited a few pages of incomplete notes on the desk of the clinic secretary and announced that it was necessary for him to go home on his vacation.

More serious are the occasional cases arising in most clinics where a client's rights are lost through student negligence in filing papers.

These errors may be remedied with little trouble. Often they are symptoms of a mental attitude of the student. As such they deserve serious study. In a sense the student is the client of the law school and has reason to expect careful consideration of his fitness for the work he is to do. Failure to investigate his reactions to the normal events of a lawyer's life ushers him unprepared into a highly competitive situation. He should have at least a hint of what will confront him and of his ability to make headway with it.

See also for examples of attempts to deal with these student viewpoints, the minutes of meetings of the staff of the Duke Legal Aid Clinic. 
and the other characteristics of a good lawyer in active practice. Second, it would be possible to ascertain with increasing accuracy the limitations of a particular student and thus help him to find the special niche where he can do his most effective work. Failure on the part of the law school to provide these individualized facilities restricts definitely its usefulness to the community and to the student. The remedy suggested is no panacea, ${ }^{\text {II }}$ nor is the machinery of clinical instruction perfected to the desired point. Yet the field is one offering research opportunities of the same fascinating sort as those engaged in by workers in the physical sciences when they go forth on expeditions to distant and little known sections of the earth. Those who know most about the clinical method in law schools have confidence in the results already achieved; they believe that with care, patience and vision a much more effective instrument may be created. Its ultimate value will be to the community but the prestige for its creation will be to the law school.

II Additional efforts to meet this situation in its broadest terms include such devices as courses on the legal profession, student bar associations, practice courts. For a compilation of material on the subject see, Report of the Committee of the Duke Law Faculty on "Courses in the Profession of the Law" (I933). 